\title{
On the Proverbial Conceptualization of the World
}

Hasmik Baghdasaryan

Yerevan State University

\begin{abstract}
$\mathrm{T}$ he term "world picture" is widely used in various modern disciplines. The physical, chemical and other pictures of the world are studied as phenomena closely related to cognitive processes for they represent the complete, more concrete and equivalent picture of a part of reality.In the given case language represents a form of expression of this conceptual (abstract - imaginary) content - a form that has been acquired by human being during his life and activity.

The consciousness of a human being and ethnos also encompasses the subjective picture of objective reality. In this respect, along with the scientific pictures of the world there are also literary, mythical, proverbial and other evaluative systems where metaphor is represented as a more effective means of creating the world picture.

Within the context of world pictures G. Brutyan mentions that it is introduced through conceptual and linguistic patterns which are not identical but reflect the relationship between the part and the whole. The conceptual pattern of the world includes the main content of world's linguistic picture. However, the mentioned conceptual pattern leaves certain peripheral parts out; those peripheral parts are of linguistic nature and contain additional information about the world, being at the same time different ranging from one language to another (Brutyan 1973:109).

The national characteristic trait of formal and semantic structures of different languages is of course explained not by the overwhelming influence that language has on mentality but by the fact that a people's language develops as a result of the cognition process. Consequently, "world picture" is created through cognitive activity, and not by language. At the same time, it would not be correct to completely ignore the impact of language on the perception of culture and reality.As mentioned by G.A. Brutyan, the result of the reverberation of the reality surrounding us is reflected through the language prism. Consequently, knowledge is of linguistic nature not only because language is a means of its realization, but also because language places its unique "stamp" on knowledge.However, as has been mentioned above, that impact is not decisive (Brutyan 1976).

The role of proverbs and sayings and idioms, in the process of the creation of the world picture has been highlighted by a number of linguists. Thus, as early as in the $19^{\text {th }}$ century, Potebnya, for instance, speaking about the unique artistic image of fables and proverbs, mentions that the latter "gives us an opportunity to replace a huge amount of thought with relatively small mental amounts", while according to G. Permyakov, proverbs and sayings are "artistic miniatures" that generalize, in a highlighted and sealed manner (or, rather, envelope more correctly), the facts of reality (Permyakov 1988:14, 57).

It cannot be denied that along with various linguistic pictures of the world there also exists a proverbial picture. The latter has its place in the mosaic of the world's linguistic picture and is perceived as a unique means of secondary semantization of the reflected
\end{abstract}


reality, expressed by proverbs and sayings. They are characterized by binary reference, since they are associated with two objects in mind.The first one is based on the material-perceptual cognition of the objective reality, whereas the second one is the result of human associative-symbolic thinking. Proverbs and sayings can also be viewed as a form of world outlook or world perception, or as pointed out by G. Gachev, they are the artistic "logic" of a nation, the mental "design" and an indicator of "which network of coordinates" a people perceives the world through and how they make up the world picture (Gachev 1988:44).

Proverbs and sayings are fixed expressions of edifying character, which are structurally expressed in simple or complex sentences. Unlike proverbs that are used figuratively, words in sayings have direct, though generalized meanings and yield a wide field of interpretations.

Being artistic elements of folk origin, proverbs and sayings reflect the life experience of the respective people, the images, symbols and even laconically enveloped motifs recurrent in their literary tradition. The selective function of language is vividly expressed through proverbs and sayings, containing rich linguocultural information. The value system has its significant place in the world's proverbial picture, forming its indivisible part.

The general essence of content and artistic form of proverbial sayings of different peoples is the result of the cross-influence of various factors and is conditioned by the degree of ethnic and linguistic kinship of the given peoples, their economic and cultural contacts, the significance of their historical experience and finally by the common universalities in their artistic and logical mentality. Without diminishing the role of the above mentioned factors in identifying commonalities in proverbs and sayings, the universality should, however, be sought in their logical content.There are examples of parallel proverbs and sayings in different languages both distantly cognate and without links of descent. In these cases the paremiological parallelism is explained by the coincidence of people's life experience. For example, the Englishmen use the saying "Faint heart never won fair lady" which has its parallel equivalent in Finnish, though the English and the Finnish belong to different language families.

Thus, proverbial meaning is anthropocentric, since it reflects the basic characteristics of human essence and human activity, but at the same time it is ethnocentric, in so far as it reflects the characteristic features of the given ethnos creating a certain type of culture, a certain national picture of the world. In the proverb stock of each language the general and national are harmoniously intertwined.

The national character of proverbial sayings is more evidently displayed in their image system, which serves the accumulation of worldviews.

Proverbs and sayings fill the ideographic network of the world disproportionately: there are many concepts which are hardly ever displayed in the proverb stock of different nations (universe, substance, science), while those conceptual fields, which reflect the everyday life of people and their relations, on the contrary, are abundantly represented in proverbs. Among the proverbs, containing national-cultural components, we consider it necessary to distinguish those proverbs which contain national - cultural elements 
of form and content. As has already been mentioned above, one and the same concept is often expressed through various images in different languages. For instance, it is a wellknown truth that a false friend is as dangerous as an obvious enemy. To express this very idea in English the proverb False friends are worse than open enemies is used, in Spanish Del agua mansa libreme Dios, que de la brava me libraré yo (literally-Deliver me, God, from the still water, and I'll deliver myself from the stormy one). To express the same thought in Italian several proverbs are used - Meglio un nemico manifesto che un falsoamico (literally - Better an open enemy than a false friend), Dagli amici mi guardi Dio, dai nemici guardo io (literally - Let God preserve me from my friends, I'll preserve myself from my enemies), as well as - L'amico falso ha il miele in bocca e il fiele nel cuore (literally - A false friend has honey in mouth and gall in heart), etc. Are these proverbs national, and, in general, should a proverb be considered national if the situation in which it is created exists in several languages, while the proverb is present only in one language? The national character of such proverbs lies in the mode of expression (image) and not in the concept. On the expression plane (according to the figurative basis) the major part of the proverbs is typical of only the given language, while on the content plane (according to the concept expressed) they may have equivalents in other languages. Such proverbs are classed with the proverbs marked with formal nationality and are distinguished from those proverbs whose national peculiarities concern their semantic aspect as well.

In the proverb stock of each national language a considerable number of sayings expressing universal truths can be found. And it is not accidental at all. The thing is that idioms, as well as sayings and proverbs are important means of evaluative-emotional description and they become out of use only in case their inner form loses its contemporaneity at a certain stage of language development. The image becomes obsolete, but not the content. This concerns only proverbs, while sayings, being devoid of figurative basis, are much more persistent, and the thoughts expressed by them are achronic, for example, in French Miaux vaut tard que jamais, in Spanish Mas vale tarde que nunca, in Italian Meglio tardi che mai, in Armenian Luul 5 nı2, pui tipptip:

In the proverb stock of every language we can come across proverbs expressing opposite meanings. This is not nonsensical at all. Is a proverb not a symbol of a typical situation? And in real life we may come across different and sometimes even opposing situations. That is why any proverb, even one which is "not true" is "true" when used in an appropriate situation. Compare the following French proverbs: L'habit fait l'homme, C'est l'habit que fait le moine (Literally - It is the gown that makes the monk) with the proverbs expressing the opposite meaning L'habit ne fait pas le moine (Literally $-A$ gown does not make a monk).

So, the proverb stock of every language embraces a unique system of cultural and universal values, which has not been a subject matter of comprehensive study yet. The problem of the "inner form" of proverbs is closely connected to the above mentioned problems, the former has not been a special subject on the comparative plane up to now, but can be an infinite source for studying the ideosincrasy of various nations. 


\section{References:}

1. Brutyan, G.A. (1973) Jazik i kartina mira. // Filosovskie nauki. N1. Moskva.

2. Brutyan, G.A. (1976) Jazikovaya kartina mira i ejo rol v poznanii. // Metodologicheskie problemy analiza yazyka. Yerevan: YGU.

3. Cantera, J.; Sevilla Muños, J.S. (2002) Pocas palabras bastan, Vida e Interculturalidad del refrán: Salamanca: Centro de la cultura tradicional.

4. Gachev, G.D. (1988) Nacionalnye obrazy mira. Moskva: Sovetskiy pisatel.

5. Mieder, W. (1994) Consideraciones generales acerca de la naturaleza del proverbio. N 3. Madrid: Paremia.

6. Permyakov, G.E. (1988) Osnovy strukturnoy paremiologii. Moskva: Nauka.

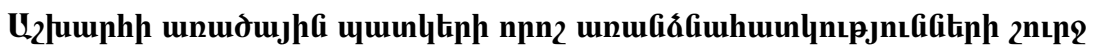

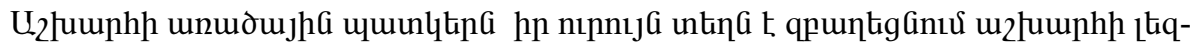

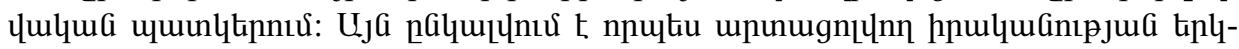

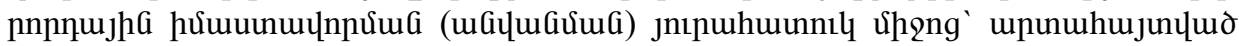

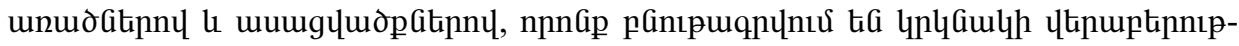

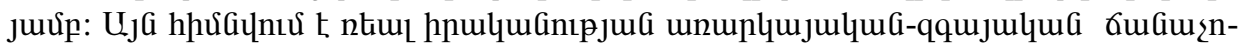

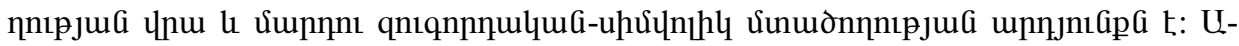

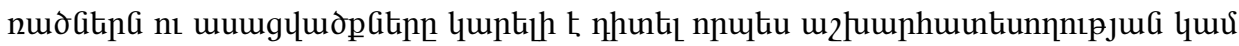

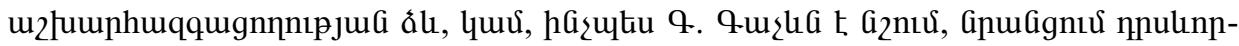

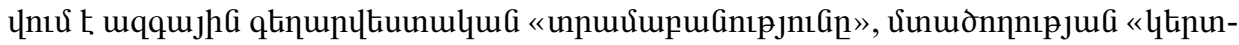

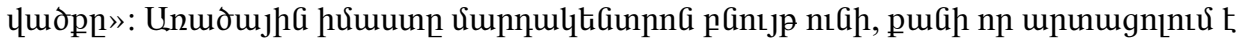

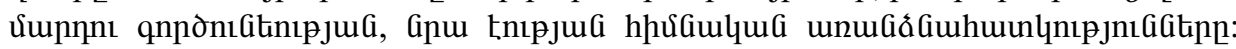

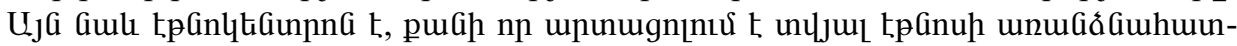

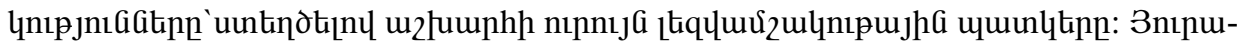

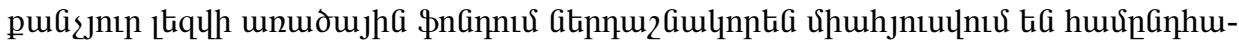
Ginıp l. uqqujhap: 